\title{
Editorial
}

Asian Business \& Management (2006) 5, 449-451. doi:10.1057/palgrave.abm.9200197

\section{Japanese research on labour and management: aims and issues}

Japanese academic research in management studies has always tended towards a practical orientation. Nonetheless, in 1991 the Japan Academy of Labour and Management was established with the aims of furthering both theoretical and practical research, both at home and in an international context. At the same time, it expressed its commitment to a critical spirit, as the driving force behind academic progress. Subsequently, though previous national conferences have focused on such areas as Japanese management and issues of employment and labour management, on the whole a characteristic of published reports has been the implicit presence of these founding tenets of the Japan Academy of Labour and Management (JALM) approach.

The five papers included in this special issue of Asian Business and Management address, from an analytical perspective, changes currently taking place in the characteristics and systems of Japanese management.

The first two writers focus on 'Japanese-style Americanization' — the change from person-oriented to task-oriented management resulting from the introduction of a performance-based approach to human resources and labour management.

Kuroda discusses the new approaches to these areas that emerged following the publication of Japanese management in the new age (1995) by the Federation of Economic Organizations (now the Japan Business Federation). The Federation maintained that trends such as increasing information technology and globalization necessitated the abandonment of rigid traditional practices such as lifetime employment and seniority-based promotion, and the introduction of more flexible employment and use of labour and promotion. The principle was that human resources and labour management should reflect trends in the marketplace, and the Federation emphasized that their proposals were in response to the current situation; and indeed movement is underway in that direction. However, at the same time, severe problems with the Japanese economy have become apparent, such as a soaring unemployment rate and number of non-regular or casual employees.

Ogoshi adds to this debate by maintaining that the so-called Japanese lifetime employment system, a feature of the high-growth period, is, along with 
the approach to wages, definitely in transformation from a typically Japanese seniority-based to a USA-derived performance-based system. However, from a democratic point of view, the loss of lifetime employment also means that workers lose guaranteed employment, while performance-based payment is causing a diminution of collective bargaining and the strength of labour unions. Therefore, Ogoshi criticizes the ongoing changes as tantamount to a conspiracy unilaterally adopted by management, and constituting, democratically speaking, a retrogressive development.

Saruta's contribution shows how, in contrast to the general trend of Japanese management, Toyota is striving to diffuse its ideology - in which lifetime employment and seniority-based payment go hand-in-hand throughout the entire company and introduce its production system in all its overseas branches. This 'Toyota Way' depends on the complete understanding and acceptance of Toyota's values and ideology by all employees; their system for diffusing values and ideology, being indispensable for their production system, is built into Toyota's human resource management and labourmanagement relations. From the point of view of human resource management, introduction of the production system and the diffusion of the Toyota Way involve close management of promotion, wage increases, small groups, transfers and positions, expansion and extension of individual duties and inhouse education and training. By these means, a situation is achieved in which the relationship between labour and management consists of full identification between the interests of the two parties, as directed and defined by the management. The Toyota Way thus creates a managerial mechanism resulting in long intensive work by employees, albeit in return for relatively high wages. However, it must be noted that the substructure supporting this system involves non-regular employees and subcontracted personnel subject to considerably less favourable conditions. It has also been observed that Toyota's management methods, where employed outside Japan, have often led to conflict between management and labour.

Tamura then discusses the ability of Japanese companies to improve products and processes, largely due to a unique combination of, on the one hand, strict Taylorist management and performance of standard operations, and on the other hand, the facility to revise standard operations at shopfloor level. In his article, he analyses the flow of operational information as stipulated by standard operating procedures, and identifies the key characteristic of Japanese industrial management as a mechanism for the standardization and improvement of operations on the basis of the range of roles carried out by production engineers and the division of roles at shopfloor level. Tamura emphasizes shopfloor role division and management of standard operations, thus presenting a view of the Japanese company markedly different 
from any suggested by more dominant theories concentrating on knowledge and skills.

Nagayama focuses on Japanese medium-sized and small companies, which have generally been looked upon as being subordinate to and dependent upon big companies, and also as being inferior in terms of labour management. Nagayama shows that it is, in fact, these companies that are trend-setters in making full and efficient use of the workforce. During the protracted economic sluggishness following the cessation of the bubble economy in 1991, and despite the collapse of many medium-sized and small companies under the effects of globalization and the increasing application of information technology, overall the scale of activities of such companies has increased. They have pioneered new commercial fields and developed new business models, resulting in the formation of innovative managerial approaches and thus the development of a range of modes for both employment and optimized workforce use, as well as unique and company-specific systems of education and training.

To summarize, then, this special issue focuses on Japanese management today, with its contributors examining its special characteristics and general condition, as well as the changes it is undergoing and problems it is facing; the ways they have approached this research reflect the characteristics of JALM. One important issue for future investigation is whether - if the direction of change in Japanese management is from person- to 'task'-orientation, as maintained by Kuroda, and in the opposite direction in US companies - there will be convergence of the Japanese and US systems. Another fascinating question is the degree to which globalization of the 'Toyota Way' is feasible, bearing in mind its close association with socio-cultural characteristics of Japan.

Nobuo Morikawa

Hiroshima Shudo University, Hiroshima-city, Japan 